\title{
GIANT AXILLARY LIPOMA
}

Ranjit Kumar Deka1, Bijit Gogoi², Nitish Kumar ${ }^{3}$, Arpan Choudhury4

1 Professor, Department of Surgery, Gauhati Medical College, Assam Medical Council.

${ }^{2}$ Assistant Professor, Department of Surgery, Gauhati Medical College, Assam Medical Council.

3 Postgraduate Student, Department of Surgery, Gauhati Medical College, Assam Medical Council.

4 Postgraduate Student, Gauhati Medical College, Assam Medical Council.

\begin{abstract}
BACKGROUND

Lipomas are benign tumours and are most common mesenchymal soft tissue tumours, composed of mature lipocytes. Frequent sites are trunk and extremities. Axilla is an uncommon site of lipoma, while giant axillary lipomas are rare. In this case report, we present a gigantic axillary lipoma. Due to the tumour mass and its long-term presence, the lipoma caused anatomical changes in the axilla making its removal challenging and difficult.
\end{abstract}

\section{KEYWORDS}

Giant, Lipoma.

HOW TO CITE THIS ARTICLE: Deka RK, Gogoi B, Kumar N, et al. Giant axillary lipoma. J. Evolution Med. Dent. Sci. 2017;6(20): 1650-1651, DOI: $10.14260 / \mathrm{Jemds} / 2017 / 362$

\begin{abstract}
BACKGROUND
Lipomas are the most common mesenchymal soft tissue tumours, benign in nature, most common site being trunk and extremities. Most of the lipomas are small and discrete swelling. They are usually asymptomatic with estimated incidence of $10 \% .{ }^{1}$ Most of them have a diameter of about 2 $\mathrm{cm}$ and rarely grow beyond $10 \mathrm{~cm}$ in their cutaneous localisation. ${ }^{2}$ They can occur as either solitary or multiple tumours located in almost any organ of the human body. However, the axillary region is an uncommon reported localisation. ${ }^{3}$ The case is of interest due to the size, location, anatomical changes and surgical challenge.
\end{abstract}

\section{CASE REPORT}

A 25-year-old man presented with a right axillary mass that had been enlarging for 10 years with no symptoms except worry about enlarging size of mass with physical disability of constant abduction of arm. Physical examination revealed a right axillary soft mass filling the axilla and right upper arm (Fig. 1).

On examination, he had a lump of about $35 \mathrm{~cm} \times 10 \mathrm{~cm} \times 8$ $\mathrm{cm}$ in the right axilla, extending right upper arm. The lump was soft in consistency and non-tender. No skin changes except for dilated vein with positive sign of pseudofluctuation and also showing typical cross fluctuation positive; right-sided brachial, radial and ulnar pulses were well felt. Power of all the forearm and hand muscles was good (Grade V). On abduction of the arm, the swelling was hanging from axilla and arm (Fig. 2).

Financial or Other, Competing Interest: None.

Submission 02-01-2017, Peer Review 22-02-2017,

Acceptance 01-03-2017, Published 09-03-2017.

Corresponding Author:

Dr. Ranjit Kumar Deka,

\#3, Hill Side,

Kushal Konwar Road

Guwahati -781003,

Assam, India.

E-mail: ranjit_deka@yahoo.co.uk

DOI: $10.14260 /$ jemds $/ 2017 / 362$

\section{(c) $(1)$}

Right axillary lipoma was excised under general anaesthesia (GA). Intraoperatively lipoma was found to be occupying whole axilla extending up to pectoralis major muscle in the chest and was densely adhered to periosteum of coracoids process and humerus. Lipoma was found to be displacing the biceps muscle as whole and lifting its short head. It was also displacing and lifting neurovascular bundle in axilla and arm and was compressing neurovascular bundle at some places. The entire lipoma along with upper arm extension was removed en masse. All the nerves ulnar, radial, median, musculocutaneous nerve and the axillary vein were carefully dissected away from the lipoma and a suction drain was kept. The drain was removed on the fifth postoperative day and the axillary sutures were removed on 10th postoperative day. The postoperative recovery was uneventful with no nerve related symptoms.

Histopathological examination in our case revealed that the lesion was composed of mature adipose tissue with interspersed thin walled blood vessels.

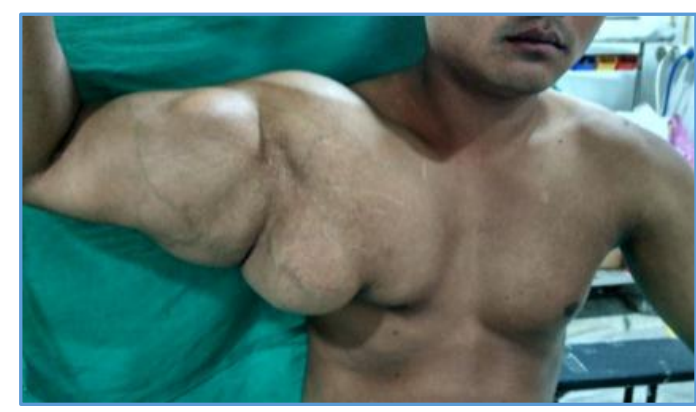

Figure 1

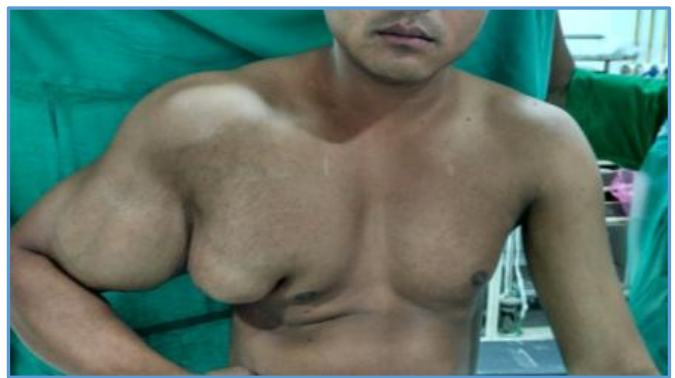

Figure 2 


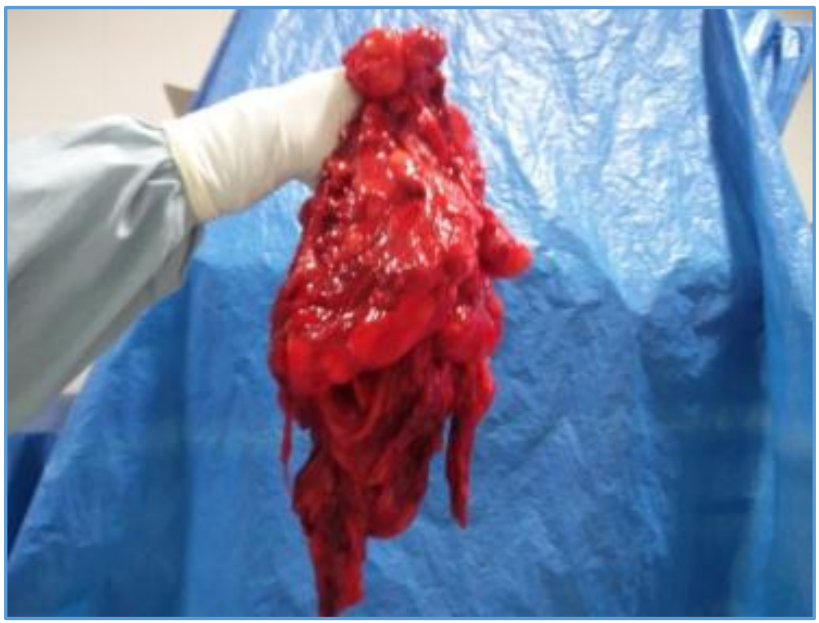

Figure 3

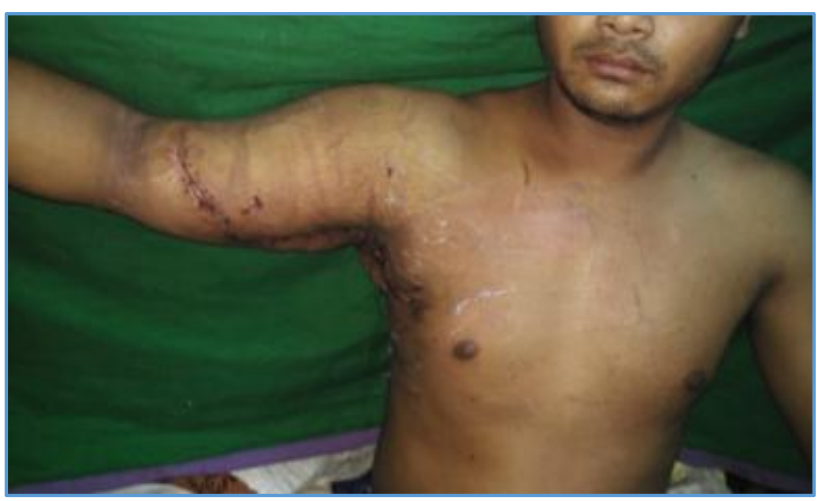

Figure 4

\section{DISCUSSION}

Lipomas are most common mesenchymal tumours that can occur in all parts of the body with an incidence of $10 \% .1,4$ Lipomas are benign tumours that are composed of mature lipocytes. Frequent sites of occurrence are trunk and extremities. ${ }^{5}$ Lipomas have been described in internal organs such as liver, lung, kidney and uterus where little or no adipose tissue is present. Most lipomas weigh only a few grams. Most lipomas are solitary and remain asymptomatic. A lipoma is categorised as 'giant' when it reaches a weight of at least $1000 \mathrm{~g}$ or a diameter more than $10 \mathrm{~cm} .{ }^{6}$ Due to the size of giant lipomas many patients experience mechanical dysfunction, pain or altered sensation resulting from compression of neighbouring structures. Many seek treatment because of social embarrassment, inability to hide the tumour from society. However, large internal lipomas can cause pain and problems due to pressure on other organs and may undergo sarcomatous changes. ${ }^{2}$ Although, the sarcomatous transformation of the giant lipoma has been reported; it is extremely uncommon in the cutaneous lipoma. ${ }^{2}$

Cutaneous lipomas are mainly cosmetic problem. Giant axillary lipomas have rarely been reported in the literature. De Andrade presented 31 cases of axillary masses and only one case of axillary lipoma was reported. 6

The aetiology of lipomas is unknown. They can be sporadic or part of an inherited disease such as familial multiple lipomatosis. It has been proposed that trauma may result in proliferation of adipose tissue due to rupture of the fibrous septa accompanied by tears of the anchorage between the skin and the deep fascia. ${ }^{7}$ Since axillary region is one of the most movables of the body, it can be exposed to microtrauma with each movement of the upper limb.

Histopathological examination in our case revealed that the lesion composed of mature adipose tissue.

The treatment for giant lipoma is complete excision and is the preferred method to avoid complications of vessel or nerve damage. Liposuction has also been reported. ${ }^{8}$ Suctionassisted lipectomy through small incisions is preferred by some surgeons due to a superior aesthetic outcome and decreased morbidity compared to open surgery. However, liposuction has also been associated with a higher risk of nerve damage and a higher recurrence rate. Lipomas with fibrous capsule formation are likely to make liposuction more difficult. 9

\section{REFERENCES}

[1] Meson H. Lipoma in clinical dermatology. Clin Dermatol 1991;4:1-2.

[2] Enzinger FM, Weiss SW. Soft tissue tumors. St Louis, CV Mosby, 1988:301-45.

[3] Terzioglu A, Tuncali D, Yuksel A, et al. Giant lipomas: a series of 12 consecutive cases and a giant liposarcoma of the thigh. Dermatol Surg 2004;30(3):463-7.

[4] Salcatore C, Antonio B, Del Vecchio W, et al. Giant infiltrating lipoma of the face: CT and MR imaging findings. AJNR Am J Neuroradiol 2003;24(2):283-6.

[5] Aydogdu E, Yyldyrym S, Eker G, et al. Giant lipoma of the back. Dermatol Surg 2004;30(1):121-2.

[6] De Andrade JM, Marana HR, Sarmento Filho JM, et al. Differential diagnosis of axillary masses. Tumori 1996;82(6):596-9.

[7] Sanchez MR, Golomb FM, Moy JA, et al. Giant lipoma: case report and review of the literature. J Am Acad Dermatol 1993;28(2 Pt 1):266-8.

[8] Rubenstein R, Roenigk HH, Garden JM, et al. Liposuction for lipomas. J Dermatol Surg Oncol 1985;11(11):1070-4.

[9] Nichetr LS, Gupta BR. Liposuction in giant lipoma. Ann Plast Surg 1990;24(4):362-5. 